\title{
SOBRE LA ESTRUCTURA CONVENCIONAL DEL TÍTULO EN LOS LIBROS ÁRABES
}

\author{
Alfonso CARMONA \\ Universidad de Murcia
}

En 1987, empecé mi artículo «La estructura del título en los libros árabes medievales» ${ }^{1}$ afirmando que «con más frecuencia de la esperable» me venía encontrando con traducciones de títulos de obras árabes que evidenciaban el desconocimiento, por parte del traductor, de la estructura tradicional, convencional, de dichos títulos; se trata de la estructura bipartita o bimembre, generalmente rimada, que ha venido utilizándose hasta casi nuestros días ${ }^{2}$, y que aunque no ha sido la única manera de dar nombre a un libro, sí ha sido la más empleada. Ahora, doce años después, constato que ni el profesor Arne A. Ambros con su espléndido «Beobachtungen zu Aufbau und Funktionen der gereimten Klassisch-arabischen Buchtitel» ${ }^{3}$, publicado en 1990, ni yo con mi breve artículo, aparecido un poco antes, hemos convencido a todos nuestros colegas, pues las interpretaciones erróneas en este campo siguen abundando. Como existe la posibilidad de que aquellas páginas mías no hayan alcanzado la suficiente difusión, quiero resumir aquí los datos y argumentos que entonces presenté, antes de añadir nuevas consideraciones y ocuparme de títulos de libros editados después o que en aquel trabajo no mencioné.

Repitamos que no todos los títulos de libros y opúsculos árabes tienen la estructura bimembre y rimada que aquí analizaré, pero basta acercarse a cual-

\footnotetext{
${ }^{1}$ Estudios Románicos 4 (1987-88-89), Murcia 1989, 181-187. Quiero agradecer ahora públicamente algunas observaciones que se me han hecho acerca de determinados detalles del artículo. Respecto a mi traducción de la expresión al-madina al-fădila, que aparece en el título del conocido libro de al-Fārābī, el académico J. Vallvé me hizo ver que mi interpretación no era correcta y que dicha expresión significa en realidad la «Ciudad Ideal», tal como ya mostró el profesor Alonso, quien tradujo: «Disertación sobre los principios relativos a las opiniones de los moradores de la Ciudad Ideal» en Al-Andalus, 26 (1961) 337. Por su parte, el profesor Arne A. Ambros me señaló que al-Tamhì li-mä fi l-Muwatta' min al-ma 'ānì wa-l-asānìd es un título que debe ser incluido en el apartado de los títulos rimados.

${ }^{2}$ En el artículo de Marcelino Villegas, «Títulos recurrentes en la neoliteratura árabe» (Actas de las II Jornadas de Cultura Árabe e Islámicas, Madrid, 1985, 613-643), no aparece ningún título bimembre y rimado en los literatos árabes del siglo xx. Sin embargo, en el campo de las ciencias islámicas o en el de las ciencias históricas, tal género de títulos ha llegado hasta este siglo.

${ }^{3}$ Wiener Zeitschrift für die Kunde des Morgenlandes 80 (1990), 13-57.
} 
quier repertorio de libros árabes escritos antes de este siglo para comprobar que son la mayoría.

Mi propuesta parte de la constatación de que, salvo alguna excepción, la rima divide el título en dos partes con significación independiente. Una excepción a esa regla la tenemos, por ejemplo, en Kitāb al-masālik wa-l-mamãlik, título que utiliza el recurso literario del taŷnis, de la paronomasia, sin establecer dos partes en el nombre del libro. Distinto es el caso de Hilyat al-awliyā' wa-țabaqāt al-asfiyā' (obra de Abū Nu 'aym al-Ișfahānī), donde la rima viene a dividir el título en dos mitades: dos sintagmas que tienen sentido completo, el primero de los cuales es el título mínimo o título breve (de hecho los autores posteriores se referirán usualmente a esta obra mencionando sólo esas dos palabras), y el segundo completa (en otros casos, repite) el contenido del primero.

Ésta es, pues, la primera función de la rima: establecer un título breve y un «subtítulo» o ampliación del título corto. Tras la primera de las dos palabras que riman hay que fijar, por lo tanto, una especie de cesura rítmica que implica un corte en el sentido; las partes separadas por la «cesura» forman unidades independientes, sintagmas con sentido completo.

Teniendo en cuenta lo dicho, podremos interpretar correctamente el siguiente título que consigno aquí a modo de ejemplo: al-Ṭali ' al-sa 'ìd al-ŷāmi ‘ li-asmā' nuŷabà' al-Sa 'ìd («La Buena Estrella, que contiene los nombres de los $n u \hat{y} a b \bar{a}^{\prime}{ }^{4}$ del Alto Egipto»). Es la rima la que nos indica dónde habremos de fijar un corte en el sentido, es decir, la que nos señala que tenemos que buscar una interpretación a al-tâli 'al-sa'id por un lado, y a al-ŷāmi ' li-asmä' $n u \hat{y} a b \bar{a}$ ' $a l-S a$ ' $i d$ por otro. Como se ve, la materia de la obra está expresada en la segunda parte. Las dos primeras palabras no parecen tener más sentido que dar pie a la rima, pues el concepto allí expresado (en este caso, al-Tă $l i{ }^{\prime}$ al-Sa 'ìd «La Buena Estrella») nada tiene que ver con el contenido del libro. Pero, además de servir a la rima, esas palabras (o palabra única, en otros casos) son algo así como un reclamo publicitario, una expresión de connotaciones positivas pensada sin duda para atraer al posible lector. Sobre esta última observación insistiré más adelante.

Así pues, en este título descarto que el participio al-ŷāmi ‘ deba vincularse semánticamente con al-tali ', sino que, en mi opinión, se refiere a la palabra kitāb implícita en el comienzo del título; aunque también podríamos considerar dicho participio como un nombre («la compilación», «el compilador») que

\footnotetext{
${ }^{4}$ Los nuŷabā' son una categoría de «santos» sufíes. Según Ibn al- 'Arabī (al-Futūhāa alMakkiyya, ed. 'Uțmān Yahyyà, El Cairo 1972, vol. II, 8), pertenecen a los «hombres del número» (riŷâl al-'adad) y hay siempre ocho en el mundo.
} 
funcionase sintácticamente como aposición del «título corto»; pues todo título (o primera parte del título completo, en la mayoría de las ocasiones) o bien adjetiva al sustantivo kitāb o a cualquier otro nombre que signifique «tratado», «compendio», «capítulo», etc.; o bien es un genitivo regido por él. Pero, sea cual sea la función sintáctica concreta que le adjudiquemos aquí a la expresión $a l$-ŷami ' $l i$-, dicha expresión, en todo caso, introduce las palabras que indican la materia del libro.

Ahora bien, en la mayoría de los títulos, esta misma función es desempeñada por la preposición $f i$ o por alguno de sus sinónimos ('alà, 'an...); ejemplos: Kitāb al-nihāya wa-l-tamām fì ma'rifat al-wată'iq wa-l-aḥkām (obra de alMatīīi (ob. 570/1174), al-Mu'rib 'an ba'ḍ 'aŷa' 'ib al-Magrib (título del libro de Abū Ḥāmid al-Garnāṭ̂̄ editado y traducido por I. Bejarano)...

El que la preposición $f i$ no está directamente vinculada a ninguna de las palabras del título corto, sino que es una extensión de kitāb, risāla, etc. (implícitos o explícitos) e indica la materia, no siempre ha sido entendido correctamente por los traductores, muchos de los cuales se ven obligados a ingeniárselas para hallar una explicación coherente que les permita vincular la partícula en cuestión a alguno de los términos de la primera parte del título, aunque en muchos casos dicho término no admita rección con $f i$, o la interpretación que quieren dar a esta partícula no sea aceptada por la lengua. Digámoslo una vez más: en los títulos en que $f i$ u otro sinónimo aparece tras la primera palabra de las dos que riman (como si fuese una especie de bisagra entre las dos partes), hay que vincular directamente dicha partícula con una palabra, explícita o no, que signifique «libro», «compendio», etc., y lo mismo sucede, por supuesto, en los títulos que no riman, como Mujtasar fi l-tibb.

Siempre me ha parecido sorprendente que los traductores que interpretan que $f i$ tiene significados muy diversos en los títulos no se hayan extrañado del hecho de que la mayoría de autores árabes hayan elegido precisamente esta partícula para enlazar con las palabras anteriores, en lugar de recurrir a otras que estén más de acuerdo con la gramática, o en lugar de haber escogido otras fórmulas (no necesariamente con preposición). ¿Qué explicación encontrarán a tamaño apego por esa palabra, y no por otra? ¿Cómo no caer en la cuenta de que, si el autor de al-Mujtär fi 'ilm al-tibb, por ejemplo, hubiera querido expresar «Lo mejor de la ciencia de la medicina» (como tradujo König), habría escrito más bien al-mujtär min...?

Es verdad que a veces el último vocablo del título corto puede ser acompañado por un complemento introducido por la partícula $f i$ o similar. En ese caso, parece plausible la opción del traductor de vincular a ese vocablo todo el sintagma que contiene la referencia explicativa de la materia. Sin embargo, tam- 
bién en esos supuestos habría que preguntarse por qué se ha elegido precisamente una expresión con la partícula de siempre, pero que no tendría allí la significación de siempre. Y además con frecuencia esas traducciones nos resultan demasiado forzadas.

Veamos un ejemplo: Ŷannat al-rị̣à fi l-taslīm li-mã qaddara Llāh wa-qaḍà es el título de una obra de Ibn 'Āṣim que ha sido traducido por M. 'A. Makkī como «El paraíso de la resignación a los designios de Dios» ${ }^{5}$. Efectivamente el nombre de acción riḍà admite la rección con $f i$ en su significado de «contentamiento con», pero yo lamento disentir del ilustre académico y buen amigo, y sigo prefiriendo separar el título en las dos partes que me marca la rima. En la interpretación de Makkī las palabras rị̣à y tastìm no sólo significan lo mismo y serían por lo tanto redundantes, sino que la segunda dependería de la primera, dando lugar a una frase que me parece un tanto torpe: «el contentarse con la sumisión a...». Es decir, si fỉ dependiera de rị̣à, sobraría al-taslìm li-, o viceversa. El traductor enmienda la plana al autor y traduce ambas palabras (con sus correspondientes preposiciones) como si no hubiera más que una. Pero, si el concepto de «resignación a» ya está expresado por al-taslim li-, cabe preguntarse por qué Ibn 'Āṣim le ha antepuesto rị̣à, si no es para constituir, junto con el regente yannat, el título corto, una expresión gramaticalmente independiente de lo que viene después.

Afortunadamente algunos investigadores, sin duda para evitar las confusiones a que estoy aludiendo, comienzan a tener la buena costumbre de poner una coma inmediatamente antes de la mencionada preposición. Uno de ellos es $\hat{Y}$ 'a far b. al-Ḥâŷy al-Sulamī quien, por ejemplo, transcribe así el título de la obra de al-Gazālī, al-Maqșad al-asnà, fi šarḥ asmā' Allāh al-ḥusnà ${ }^{6}$. También el citado A. A. Ambros pone una coma ante über cuando traduce títulos que llevan $f i$; por ejemplo, «Das kostbare Juwel, über die Biographien der Kalifen und Sultane» ${ }^{7}$.

No todos los títulos rimados tienen una estructura en que el segundo «verso» contenga la referencia explicativa de la materia. En muchas ocasiones la

${ }^{5}$ Al-Qantara, 19 (1998), 220.

${ }^{6} \mathrm{~J}$. Ben el-Haj Soulami en la introducción a su edición de la obra anónima Mujtașar Nuzhat al-afkär..., Tetuán, 1417/1996, 13.

${ }^{7}$ Página 13 del citado artículo de A. A. Ambros. 
partícula que une los dos sintagmas que riman es wa- (recuérdese el ejemplo que antes he aducido: Hilyat al-awliyā' wa-țabaqāt al-asfiyā'). En ese supuesto, el segundo sintagma completa o repite la información que suministra el primer sintagma o título usual.

Por el contrario, en otros casos (no muy numerosos) de títulos rimados, la segunda mitad sí depende sintácticamente de la primera. El lazo de unión será la partícula adecuada. Un buen ejemplo lo constituyen los títulos que empiezan por al-i 'lām bi-, de los que citaré tan sólo dos: Kitāb al-I'lām bi-išārāt ahl alilhām («Información acerca de las alusiones simbólicas ${ }^{8}$ de los inspirados», tratado de Ibn al-'Arabī), y al-I'lām bi-man ḥalla Marrākuš wa-Agmāt min ala'lām («La información acerca de los sabios que residieron en Marrākuš y Agmāt»). Al-Takmila li-Kitāb al-Sila es otro ejemplo de «preposición-bisagra» que depende sintácticamente de la palabra anterior.

Evidentemente, eso mismo (el que la partícula bisagra deba ser eventualmente vinculada con la palabra precedente) puede acontecer con $f i$ o sus sinónimos, y a ello aludiré en el apartado IV .

Por otro lado, existen bastantes títulos en los que hallamos varias rimas, en lugar de una sola; por ejemplo: al-Anìs al-mutrib bi-raw ̣̂ al-qirțās, fi ajbār mulūk al-Magrib wa-ta'rīj madinat Fās. En estos casos, es la rima que se encuentra al final del título la que nos sirve para dividir éste en las dos partes consabidas. Pluralidad de rimas y paralelismos aparecen en el largo título que el almeriense al- 'Udrī dio a su libro Tarși ' al-ajbār wa-tanwī' al-ātār wa-l-bustān fi garā'ib al-buldān wa-l-masālik ilà ŷamī 'al-mamālik. Cuando en mi artículo sobre los títulos mencioné esta obra, sólo acerté a señalar su «peculiar y compleja disposición de las rimas» y el hecho de que lo que yo veía entonces como la primera mitad no era la «consagrada fórmula de una única y concisa expresión»; posteriormente he caído en la cuenta de que este título encierra en realidad tres, cada uno de los cuales está además estructurado a partir de un recurso estilístico y gramatical diferente. Quienes hayan usado esta obra podrán fácilmente corroborar que esos tres libros que ahora mencionaré están realmente allí incluidos, aunque no uno tras otro, sino que el triple título nos está indicando que son tres las materias del libro. Y es precisamente la disposición de las rimas la que me ha dado la llave para desenmarañar la aparente complejidad de lo que creíamos un título único aunque notablemente largo ${ }^{9}$.

\footnotetext{
${ }^{8}$ En esta traducción de išārāàt sigo a Pablo Beneito.

${ }^{9} \mathrm{El}$ editor de los fragmentos de esta obra referidos a al-Andalus, al-Ahwānī, se limitó a señalar que el título era especialmente largo, sin buscar ninguna explicación (pág. zāy de la introducción a su ed., Madrid, 1965).
} 
Veamos: Tarșì ‘ al-ajbār wa-tanwī ‘ al-ātāor ${ }^{10}$ («Taracea de noticias y clasificación de tradiciones») indica que estamos ante un libro de historia, que, como sabemos, contiene valiosas informaciones sobre al-Andalus; al-Bustān, $f i$ garā'ib al-buldān («El jardín, libro que trata de las curiosidades de los países») alude a que también es una geografía fantástica, una enciclopedia de hechos insólitos; al-Masālik ilà ŷamì al-mamālik («Los caminos que conducen a todos los reinos») señala que es igualmente un libro de itinerarios y de geografía en general (física, humana y política).

\section{III}

Las palabras empleadas en la expresión preliminar que constituye el nombre corriente de un libro las encontramos con gran frecuencia repetidas en más de un título. Así, por ejemplo, según el cálculo realizado por Arne A. Ambros, en el estudio citado, a partir de un corpus de 1.690 títulos contenidos en el conocido repertorio de Brockelmann, la palabra durr «perla» aparece en 59 ocasiones, y el término tuhfa «regalo» lo hallamos en 49 de esos nombres de libros (p. 29). Y es frecuente incluso el hecho de que un mismo título corto sea adoptado por varios autores.

El profesor Ambros ha resaltado también en su trabajo el hecho de que, cuando la primera parte del título consiste en una iḍa fa, el genitivo modificador se refiere muy frecuentemente al hombre, que debe ser identificado por lo general con el tipo de lector a quien se dirige más particularmente el libro (p. 32). Un ejemplo entre miles: I'timād al-ḥukkām, fi masā'il al-aḥkām de Abū 'Alī Hasan b. Zakkūn. Eso sucede también, podemos añadir, cuando esa primera parte del título consiste en un sustantivo cuya extensión es un sintagma preposicional; por ejemplo: al-Mufid li-l-hukkām. En ambos casos, esa expresión tiene la intención de ser un reclamo publicitario, que proclama que ese producto es útil, conveniente, necesario, imprescindible, etc., para una determinada categoría de personas (en los dos ejemplos aducidos, los jueces y magistrados).

Una bella muestra de otra modalidad de lo que estamos comentando lo constituye el nombre que al-Qalqašandī (ob. 821/1418) dio a su obra Șubh al$a$ 'šà, fi șinā 'at al-inšă'. En este caso la palabra $a$ ' ̌̌à no indica ninguna clase determinada de profesionales (que el libro está destinado a los redactores de las

\footnotetext{
${ }^{10}$ Es precisamente tarși $^{\circ}$ el tecnicismo que designa el paralelismo aquí usado como bello recurso estilístico.
} 
cancillerías, o a los aspirantes a serlo, se sabe por el subtítulo), sino que las dos palabras del título corto componen una hermosa metáfora y una decidida promesa, que desgraciadamente no podemos traducir con una expresión tan concisa y rotunda como en árabe: «luz del alba para quien ve mal por la noche». Es decir, el libro promete ser, para aquellos secretarios que crean tener carencias en su oficio, como la llegada de la luz del día para quien no es capaz de ver en la oscuridad de la noche.

Y cuando no hay ninguna alusión al tipo de destinatario a quien la obra podría ser útil, el título suele comparar con una joya u otro objeto precioso el producto salido de la pluma del escrito; por ejemplo, Ŷawăhir al-adab, fi ma'rifat kalām al-'arab, título de un tratado de al-Irbillī. $\mathrm{O}$ alude al buen propósito del autor; recuérdese: al-Maqșad al-asnà (título de al-Gazālī), o alMaqșad al-mahmū (formulario notarial de al-ŶYazīrì recientemente editado por Asunción Ferreras), etc.

IV

Uno de los pocos autores que se han ocupado de este tema es G. M. Wickens, en cuyo «Notional Significance in Conventional Arabic "Book" Titles: Some Unregarded Potentialities» ${ }^{11}$, encontramos interesantes y muy pertinentes observaciones sobre la traducción que se viene dando a ciertas palabras y expresiones en determinados títulos. Sin embargo, el hecho de que este arabista olvide el papel sintáctico de la partícula $f i$ presente en buena parte de los títulos que él traduce, le hace caer, a su vez, en errores, algunos de los cuales voy a intentar mostrar. Él interpreta, por ejemplo, Ša darāt al-dֵahab fi ajbār man dahab como «The Parings of Gold, Being the Accounts of Those Who Have Departed/Gone Before». Independientemente del hecho de que podamos considerar que el autor árabe proclama en su título que las informaciones que ha reunido son partículas (o «raspaduras» en la versión de Wickens) de oro, dicha traducción ignora la presencia de $f i$ o desiste de encontrarle una función y un significado permitidos por la lengua árabe. Esa partícula no puede ser traducida como Being; lo que Wickens parece haber entendido se diría en árabe Ša darāt al-dahab wa-hiya ajbār man...

Otro ejemplo es su traducción del nombre de la obra de Bahā' al-Dīn alIbšīhī (m. después de 850/1446), al-Mustațaf fi kull fann mustazraf: «The

${ }^{11}$ Bosworth, C. E., et alii (ed.), Essays in Honor of Bernard Lewis. The Islamic World. From Classical to Modern Times, Princeton, New Jersey, 1989, 369-388. 
Gleanings/Croppings/Reconditioned Items from Every/Any Area of Interest», interpretación que recuerda la que diera el traductor occidental de la obra, G. Rat, quien entre 1899 y 1902 publicó una traducción del Mustatraf llamándolo Recueil de Morceaux choisis çà et là dans toutes les branches des Connaissances réputées attrayantes. Desde mi punto de vista, al-Mustatraf (El/lo considerado singular») es el título corto del libro; la materia viene expresada en el subtítulo Fi kull fann mustazraf «Que trata de todo arte juzgado hermoso». La interpretación de Rat, seguida por Wickens, se basa sin duda en que el resultado que se obtiene vinculando $f \bar{l}$ a mustatraf parece convenir a una obra que puede considerarse una antología. Quizá lo que suceda es que, en ésta como en otras ocasiones, el autor juegue con la doble posibilidad de poder considerar la preposición no sólo dependiente de kitāb, sino de la palabra principal o de alguna de las palabras con las que se da título al libro, vocablos que, por lo general, admiten algún tipo de extensión o rección. Sería un recurso semejante al que hoy tanto emplean nuestros publicistas: la polisemia, la connotación, el doble sentido o la doble lectura... Y un buen ejemplo de ello lo tendríamos en el Mustatraf: pero, sólo si consideramos este participio como un genitivo regido por kitäb, es decir, un neutro en nuestra concepción gramatical, podremos entender: «(Libro de) lo considerado singular en todo arte tenido por bello». Ahora bien, si entendemos que el principio al-mustatraf adjetiva al nombre al$k i t a ̄ b$ (como es mi parecer) tal interpretación será imposible.

Pero el autor cuyo trabajo comentamos no ignora el valor que en un título puede tener la preposición $f i$, aunque sólo lo aplica en contadas ocasiones. En efecto, en su clasificación de los títulos (pp. 383-384), el segundo apartado lo ocupan títulos como al-Kāmil fi..., al-Käfi fỉ... donde, según declara, la preposición «introduces the general reference to the topic itself: history, medicine, geometry, etc.», pero sorprendentemente no extiende esa constatación al resto de títulos que él llama «The more elaborate, two-part title, linked by fi or $w a-»$ (p. 384). Creo que la explicación está en las dos últimas palabras de esa cita («or $w a-»)$. Para él ambos tipos («linked by $f i$ or $w a-»)$ de títulos «más elaborados» tienen la misma estructura, siendo la rima la única razón de que haya dos partes. Sin embargo, desde el punto de vista sintáctico, es evidente que estamos ante dos estructuras diferentes. En los títulos donde la conjunción wahace de bisagra, la segunda parte tiene el mismo rango gramatical que la primera y lo que hace es añadir un elemento nuevo a la información que ha empezado a transmitir el autor sobre su obra en el primer sintagma del título. Por el contrario, la partícula $f i$ establece una relación de subordinación, ya sea con respecto a kitāb, risāla, etc., ya sea con respecto a alguna de las palabras del título corto, como muchas veces erróneamente se supone. 
Una prueba más de que Wickens no ignora el papel que $f i$ puede desempeñar en un título es su afirmación (p. 377) de que en los títulos hay que sobreentender dos palabras preliminares como risāla fi u otras semejantes. Pero la realidad es que en la mayor parte de los casos sólo hay que sobreentender una palabra (kitāb, risāla...), pues la partícula $f i$ ('alà, 'an...) está explícita, y que lo que él afirma sólo sucede en algunos libros cuyo título anuncia directamente su contenido; ejemplo: Ijtilăf al-fuqahā', donde hay que entender en realidad: Kitāb $f i$ jtilāf al-fuqahā'. Pero, su convencimiento de que, en los títulos rimados, la segunda parte depende sintácticamente de la primera le impide ver que la partícula que él presupone con toda razón implícita en un título como el del ejemplo anterior es la misma que aparece, explícita, en tantísimos otros nombres de libros. Para él, como para muchos otros, solamente la rima nos hace ver dos partes en el título; es decir, la cesura rítmica no implicaría corte en el sentido. Su opinión de que $f i$ es el enlace que subordina la segunda parte a la primera, la expresa claramente al rechazar la posibilidad de que el libro de Ibn al'Arabī, Fușūṣ al-hikam wa-jușus al-kilam, sea, como registra Brockelmann, Fușūs al-ḥikam fi..., argumentando (pp. 379-380): «While the former [=fi] might be plausible enough in most two-part titles, the latter alternative [=wa-] seems more likely in the present instance, since the two parts are here fully complementary and do not stand in any apparent posture of relative subordination or qualification.»

\section{$\mathrm{V}$}

Por último, y como aplicación de cuanto acabo de exponer, permítanseme unas observaciones sobre la traducción del título de la obra de Ibn 'Iyāạ, Madāhib al-ḥukkām, fi nawāzil al-ahkām, cuya traductora, Delfina Serrano, ha entendido como «La actuación de los jueces en los procesos judiciales» (véase mi reseña del libro en el volumen XX de Al-Qanțara). Dicha traducción indicaría que estamos ante un tratato de derecho procesal, siendo así que, por el contrario, el contenido de la obra es de derecho material o sustantivo. Creo que no es una simple cuestión de elección de las palabras, sino de no haber tenido en cuenta el hecho de que éste es uno de esos títulos estructurados en dos partes, la segunda de las cuales está introducida por la preposición $f i$, como es muy habitual. La primera parte es propiamente el título de la obra: una expresión (recordémoslo) de connotaciones muy positivas, fácil de retener y prometedora en cuanto al interés de la obra, una expresión de dos palabras (como también es muy habitual), la última de las cuales rima con la 
segunda parte del título, que es una especie de subtítulo donde se da referencia de la materia del libro.

En este título, el sintagma regido por $f i$ podría fácilmente tomarse como extensión de madāhib, y así lo ha entendido D. Serrano, pero le ha dado a ese plural el significado de «actuación», lo que puede llevar a la confusión a que he aludido. No obstante, incluso entendiendo la palabra en su acepción más general de «opiniones, doctrinas», el título parecería indicar (si se hace depender $f i$ de madāhib, lo que significaría: «las opiniones de los jueces en los casos judiciales») que la obra sólo contiene las soluciones aportadas por jueces a diversos casos judiciales; pero el libro no es una recopilación de sentencias o precedentes judiciales, sino que contiene sobre todo dictámenes, emitidos por juristas en calidad de muftíes, no en calidad de jueces.

La solución está en: 1) partir del hecho de que Mad̄āhib al ḥukkām es el título, y que nawāzil al-aḥkām es la materia, y que este último sintagma introducido por $f i$ es extensión de kitāb, palabra que siempre está, al menos implícita, en un título de libro; y 2) tener en cuenta que el término madhab (pl. madāhib), además de «doctrina, opinión», puede significar «el hecho de refugiarse (en alguien)». En efecto, Kazimirski indica que el verbo dahaba (del que madhab es uno de los nombres de acción) significa también «refugiarse». Por otra parte, es con el sentido de «lugar de refugio» (véase el Supplément de Dozy) como emplea Ibn Madrūn de Silves la palabra madhab en su comentario de la célebre casida de Ibn 'Abdūn al-Fihrī (ambos autores son, precisamente, contemporáneos del qā ç̣ 'Iyāḍ, y el segundo de ellos fue maestro del ceutí). Partiendo de estos datos, y de lo que antes hemos comentado acerca de que el título corto es con mucha frecuencia una expresión que proclama que el libro es del máximo interés para un determinado público, propongo entender el vocablo madāhib como «refugios» (en caso de apuros, es decir, ignorancia o duda). Si tengo razón, Mad̄āhib al ḥukkām querría expresar lo mismo que títulos como I'timād al-hukkām, Mufid li-l-hukkām o Tabșirat al-ḥukkām, es decir, una expresión «publicitaria» que quiere mostrar no sólo quiénes son los destinatarios de la obra, sino también su interés como útil manual o vademécum que sacará de apuros a quienes hayan sido designados administradores de la justicia.

\section{RESUMEN}

La mayoría de los títulos de libros árabes de época pre-moderna muestran una estructura bipartita o bimembre, generalmente rimada, en la que las dos partes tienen, 
también por lo general, significación completa e independiente. Esta estructura tradicional es ignorada por aquellos que traducen la segunda parte como una extensión de la primera. En el artículo se señala también que la razón de esa división en dos mitades es dotar al libro de un título breve, de connotaciones positivas y fácil de memorizar, contenido en la primera mitad, y luego un subtítulo (que constituye la segunda parte) que exprese realmente la materia del libro.

\begin{abstract}
Most pre-modern Arabic book-titles have a bipartite, generally rhyming structure, in which both parts have, also in general, a complete and independent significance. This conventional structure seems to be ignored by those who translate the second part as an extension of the first one. The reason for this division in two parts is to provide the book with a short, easy to learn title, contained in the first half of the entire title, and a «subheading», which is contained in the second half, introducing the general reference to the topic itself.
\end{abstract}

